\title{
Correction to: Skeletal records of bleaching reveal different thermal thresholds of Pacific coral reef assemblages
}

\author{
Nathaniel R. Mollica ${ }^{1}$ - Anne L. Cohen ${ }^{2}$ (D) Alice E. Alpert ${ }^{1,3} \cdot$ Hannah C. Barkley $^{1,4,5}$ • \\ Russell E. Brainard ${ }^{5} \cdot$ Jessica E. Carilli ${ }^{6,7}$ - Thomas M. DeCarlo ${ }^{1,8}$. \\ Elizabeth J. Drenkard ${ }^{1,9} \cdot$ Pat Lohmann $^{2} \cdot$ Sangeeta Mangubhai $^{10}$. \\ Kathryn R. Pietro ${ }^{2} \cdot$ Hanny E. Rivera ${ }^{1,11} \cdot$ Randi D. Rotjan ${ }^{11}$ - Celina Scott-Buechler ${ }^{2,12}$ • \\ Andrew R. Solow ${ }^{2}$ Charles W. Young ${ }^{4,5}$
}

Published online: 19 June 2019

(C) Springer-Verlag GmbH Germany, part of Springer Nature 2019

\section{Correction to: Coral Reefs \\ https://doi.org/10.1007/s00338-019-01803-x}

Figure 2 in the original article has been updated with this figure 2 due to discrepancies related to incorrect mapping with one of the islands.

The original article can be found online at https://doi.org/10.1007/s00338-019-01803-x.

Nathaniel R. Mollica

nmollica@whoi.edu

$\triangle$ Anne L. Cohen

acohen@whoi.edu

1 MIT-WHOI Joint Program in Oceanography, Woods Hole Oceanographic Institution, Woods Hole, MA 02536, USA

2 Woods Hole Oceanographic Institution, Woods Hole, MA 02536, USA

3 Present Address: U.S. Department of State, Washington, DC 20520, USA

4 Present Address: Joint Institute for Marine and Atmospheric Research, University of Hawaii at Manoa, Honolulu, HI 96822, USA

5 Ecosystem Sciences Division, NOAA Pacific Islands Fisheries Science Center, Honolulu, HI 96818, USA

6 Australian Nuclear Science and Technology Organization, New Illawarra Rd, Lucas Heights, NSW 2234, Australia

7 Present Address: Energy and Environmental Sciences, Naval Information Warfare Center Pacific, 53475 Strothe Rd., San Diego, CA 92152, USA
8 Present Address: Red Sea Research Center, Division of Biological and Environmental Science and Engineering, King Abdullah University of Science and Technology (KAUST), Thuwal, Saudi Arabia

9 Present Address: Geophysical Fluid Dynamics Laboratory, NOAA, Princeton, NJ 08540, USA

10 Wildlife Conservation Society, 11 Ma'afu Street, Suva, Fiji

11 Biology Department, Boston University, Boston, MA, USA

12 Department of Earth and Atmospheric Sciences, Cornell University, Ithaca, NY 14850, USA 


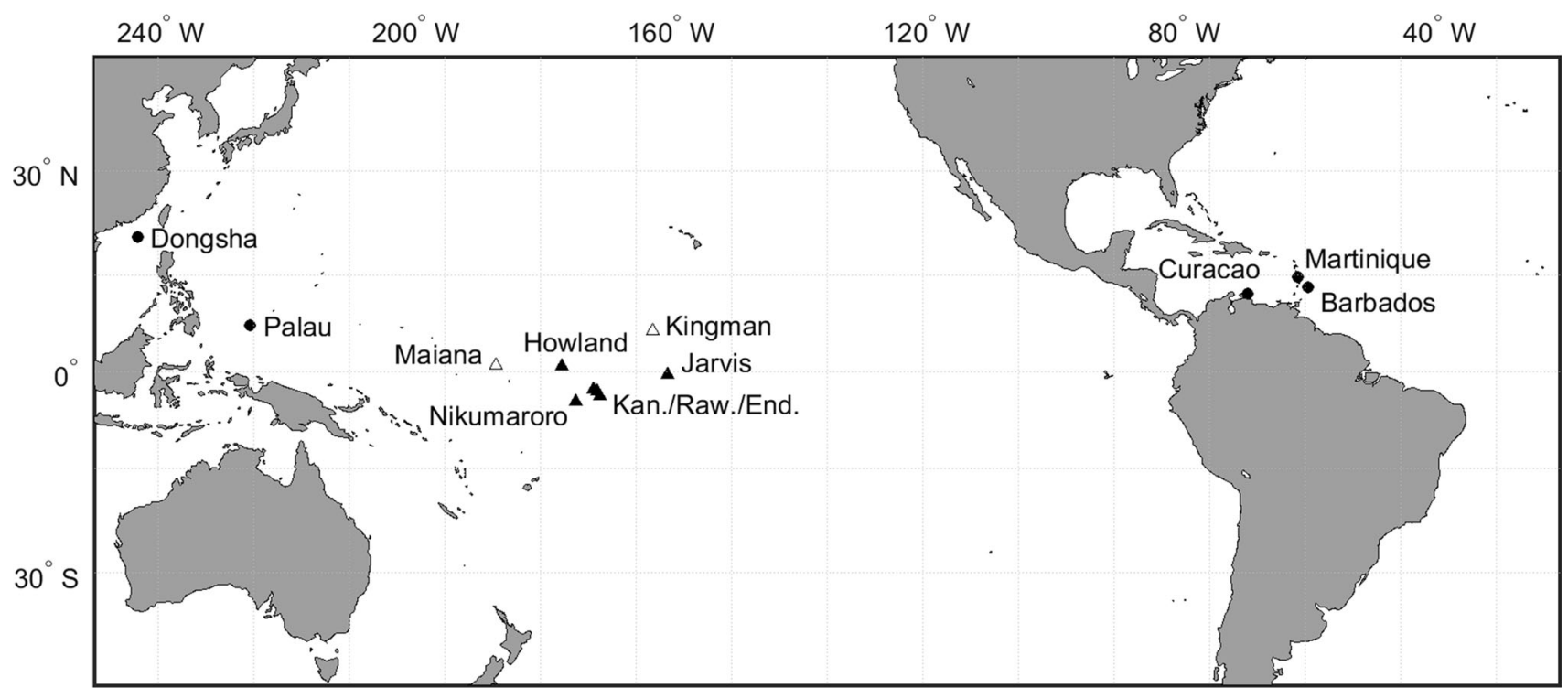

Fig. 2 Location of coral reefs included in this study. Cores collected on reefs denoted by black circles contributed to the stress bandbleaching severity calibration only. White triangles denote reefs that did not contribute to the calibration due to the absence of observational data, but for which bleaching histories were reconstructed. Black triangles denote reefs that both contributed to the calibration and for which bleaching histories were reconstructed. Kan./Raw./End. refers to the Kanton, Rawaki, and Enderbury Islands

Publisher's Note Springer Nature remains neutral with regard to jurisdictional claims in published maps and institutional affiliations. 